\title{
Improving Mental Health Literacy in Post-Secondary Students: Field Testing the Feasibility and Potential Outcomes of a Peer-Led Approach
}

\author{
Chris Gilham, and Erin L. Austen \\ St. Francis Xavier University \\ Yifeng Wei, and Stanley Kutcher \\ Dalhousie University
}

\begin{abstract}
Transitions (2nd edition) is an evidence-based life-skills resource designed to help post-secondary students transition from high school to college or university. This study was an on-campus evaluation of peer-led seminars of the mental health content from Transitions. A cross-sectional survey was conducted to assess the mental health literacy of three groups of students: master trainers, student trainers, and seminar participants. Post-seminar, there were significant improvements in mental health knowledge and helpseeking, two key components of participants' mental health literacy. This peer-led approach is a feasible option with the potential to improve student mental health literacy within a short time frame.
\end{abstract}

Keywords: mental health literacy, students, Transitions, peer-led seminars, college, university

Chris Gilham, Department of Teacher Education, St. Francis Xavier University, Antigonish, Nova Scotia; Erin L. Austen, Department of Psychology, St. Francis Xavier University, Antigonish, Nova Scotia; Yifeng Wei, Department of Psychiatry, Dalhousie University, Sun Life Financial Chair in Adolescent Mental Health, IWK Health Centre, Halifax, Nova Scotia.; and Stanley Kutcher, Department of Psychiatry, Dalhousie University, Sun Life Financial Chair in Adolescent Mental Health, IWK Health Centre, Halifax, Nova Scotia.

The authors would like to thank the participants of this study, including the master trainers and student trainers.

Correspondence concerning this article should be addressed to Chris Gilham, Department of Teacher Education, St. Francis Xavier University, PO Box 5000, Antigonish, NS, Canada, B2G 2W5. Phone: (902) 867-3764. Email: cgilham@stfx.ca 


\section{RÉSUMÉ}

Transitions ( $2^{\mathrm{e}}$ édition) est une ressource de développement des compétences pratiques fondée sur des données probantes qui vise à aider les étudiants de niveau postsecondaire à faire la transition de l'école secondaire au collège ou à l'université. Cette étude constituait une évaluation sur le campus de séminaires dirigés par des pairs portant sur le contenu en santé mentale de Transitions. Une enquête transversale a été réalisée pour évaluer le niveau de sensibilisation de trois groupes d'étudiants (maîtres formateurs, étudiants-formateurs et participants aux séminaires) en matière de santé mentale. À l'issue des séminaires, des gains notables avaient été réalisés en ce qui concerne le niveau des connaissances et les demandes d'aide formulées, deux composantes clés de la sensibilisation des participants en matière de santé mentale. Cette approche éducative dirigée par des pairs constitue une option viable qui pourrait permettre d'améliorer rapidement la sensibilisation des étudiants en matière de santé mentale.

Mots clés : sensibilisation en matière de santé mentale, étudiants, Transitions, séminaires dirigés par des pairs, collège, université

\section{BACKGROUND}

University life marks a significant transition period for many students; it is often the first time that they are living on their own or at least away from family supports. It is also a time when they are trying to balance increased school demands with new social pressures, and a time when many are faced with significant financial strain. Furthermore, the age range of students falls within the life-span window in which most mental illnesses can be first diagnosed (Kessler, Amminger, Aguilar-Gaxiola, Alonso, Lee, \& Ustun, 2007) and mental health and mental disorders are increasingly being recognized as important areas of need on college campuses (American College Health Association, 2016; Canadian Association of College \& University Student Services and Canadian Mental Health Association, 2013; Holmes, Silvestri, \& Kostakos, 2011; Prince, 2015; Storrie, Ahern, \& Tuckett, 2010).

Mental health literacy is foundational for mental health promotion, prevention, and care (Kutcher, Wei, \& Coniglio, 2016; Kutcher, Wei, Costa, Gusmao, Skokauskas, \& Sourander, 2016) and the early diagnosis and treatment of mental disorders is associated with better social, academic, and vocational outcomes (Larsen et al., 2011; Perkins, Gu, Boteva, \& Lieberman, 2005; McGorry, Purcell, Goldstone, \& Amminger, 2011), whereas untreated mental illness can have a negative impact on physical health, academic outcomes, and future job prospects (Ettner, Frank, \& Kessler, 1997; Kessler, Foster, Saunders, \& Stang, 1995; Mojtabai et al., 2015; Scott \& Happell, 2011). Suicide is the second leading cause of death among Canadian youth (Navaneelan, 2012), and is often associated with mental disorders that presented during this period (Mann, 2002). Since mental health literacy (MHL) is a foundational element related to mental health, it is important that students develop age appropriate MHL capacity that will assist them to understand how to obtain and maintain good mental health, understand mental disorders and their treatments, decrease stigma, and enhance help-seeking efficacy (Kutcher, Wei, \& Coniglio, 2016; Kutcher, Wei, Costa, Gusmao, Skokauskas, \& Sourander, 2016). 
MHL interventions must be developmentally appropriate (Jorm \& Kitchener, 2011; Kutcher, Wei, \& Coniglio, 2016; Milin et al., 2016; Ross et al., 2012) and on college campuses these must consider the emerging independence of students, the interdependence of mental health, health and life-skills competencies, and the role of peer interaction as a source of informal health support (Gulliver, Griffiths, \& Christensen, 2010; Reavley, McCann, \& Jorm, 2012; Rickwood, Deane, Wilson, \& Ciarrochi, 2005). Transitions (2nd edition) is a resource (Kutcher, 2014) developed for use on college campuses respecting this MHL developmental focus. Available in hard copy, ebook, and mobile APP formats, Transitions provides students with information on a variety of life-skills topics that are increasingly relevant at this stage in their lives such as time management, healthy relationships, finances, sexual health, etc. In the Transitions resource, these are woven seamlessly into numerous mental health topics. Taken together they cover the key components of student-identified information needs for campus life (American College Health Association, 2013; 2016).

The impact of Transitions (2nd edition) on college student MHL has demonstrated positive results in two previous studies. Using the first edition of Transitions, Potvin-Boucher et al. (2010), in a survey of first-year students on a number of campuses in the Province of Nova Scotia, Canada, reported that 95\% of respondents liked the materials, $40 \%$ discussed them with a friend, and $16 \%$ sought help or planned to seek help for a mental illness because of what they read. A replication study using the second edition of Transitions conducted on the Dalhousie University Campus (Halifax, Nova Scotia) found almost identical results (Kutcher, Wei, \& Morgan, 2015), with most students indicating that Transitions had a positive impact on their knowledge, attitudes, and help-seeking efficacy. Additionally, almost $90 \%$ reported they would recommend the resource to someone they knew, indicating a high degree of acceptance by students. Both of these studies, however, simply surveyed student populations and did not tie the use of the resource to any specific delivery process nor did the studies report on objectively assessed changes in various MHL components in those students who were exposed to the resource. Thus, additional assessment of the impact of Transitions needs to take into account more formalized methods of delivery of the resource as well as a more robust assessment using objective measures of its impact on various components of MHL.

One method for the delivery of health information on college and university campuses is a peer-education approach (Parkin \& McKeganey, 2000). Although there is much variation in the method of implementation, the delivery typically relies on trained individuals who are similar in age or experience to the recipients of the information. This approach has been used to encourage a variety of positive health behaviour changes including a reduction in harmful drinking (e.g., White, Park, Israel, \& Cordero, 2009), sexual health promotion (e.g., Brigham et al. 2002), and improvements in levels of physical activity (e.g., Best, Miller, Eng, \& Routhier, 2016). Some studies have demonstrated promising use of this approach in campus mental health interventions (Kirsch et al., 2014; Thombs et al., 2015).

While often used, this approach has not received wide evaluation of impact and, when studied, evidence for its effectiveness in some health-related areas has been mixed (Lindsey, 1997; Mellanby, Rees, \& Tripp, 2000; Miyamoto \& Sono, 2012; O’Hagan, Cyr, McKee, \& Priest, 2010; White et al., 2009). In research that has examined the issue of specificity of impact, peer-education approaches have been generally found to be applied in combination with other support strategies, so it can be difficult to evaluate the unique impact of the peer-to-peer approach on its own (Eysenbach, Powell, Englesakis, Rizo, \& Stern, 2004). Additionally, 
this approach is often targeted to an at-risk population rather than more broadly in a universal application model (Bulanda, Bruhn, Byro-Johnson, \& Zentmyer, 2014).

These caveats notwithstanding, we decided to evaluate a peer-delivered seminar-style presentation of selected content from the mental health section of the second edition of the Transitions resource as a campus MHL intervention and to evaluate its impact using pre-post measures of knowledge, attitudes, and helpseeking efficacy. We tested a waterfall application model where a small group of master trainers (MTs) were trained on MHL content derived from Transitions by the resource developer and one of the authors of this paper (SK and YW). These master trainers then trained a larger number of student trainers (STs) who then held seminars for students in on-campus residence settings. To our knowledge this is the first such evaluation of this resource applied in this manner on any college campus.

\section{METHODS}

Following campus Research Ethics Board approval, the lead researchers at the field test site (CG and EA) collaborated with the Students' Union, the student-led Mental Health Student Society, the Health and Counselling Centre, and Residence Services to elicit support from key on-campus stakeholders. The goal of developing, delivering, and evaluating peer-led mental health literacy seminars in residences on campus was approved for the campus and a waterfall delivery model was adopted.

This model involved training students in three progressively larger tiers. First, a group of MTs were recruited for participation in the project. This group consisted of 13 upper-level students who were recruited from the Mental Health Student Society, from Residence Services (e.g., resident assistants), and from selected upper-level courses with a health focus (e.g., Health Psychology, Mental Health in Education). MTs first reviewed the Transitions resource to identify key mental health literacy components that they felt were particularly relevant for their peers. They communicated these key components to the training program content developers (SK and YW) who created a half-day MHL training program based on their feedback, designed for peer-led university student seminars.

This MHL presentation was then taught to the MTs in a day-long training session that was led by the developers. A MHL survey assessing knowledge, attitudes, and help-seeking efficacy was administered to MTs immediately before and after the training session. Further feedback from the MTs on the presentation materials was provided in an open forum; the training program developers used that feedback to create an approximately 40-minute long seminar-style version of the original presentation, suitable for a peer-led campus MHL seminar.

The second tier of mental health training involved a subset of eight of the master trainers. Student trainers $(n=16)$ were selected from among those who responded to a similar recruitment approach as that used for the MTs (e.g., health-related courses, resident assistants). They were guided through the seminar training program by the MTs over the course of 1.5 hours. Student trainers were given time to discuss the material with the master trainers and to ask questions. Two of the researchers (CG and EA) were present to address any questions that arose. Individual roles in the presentations were agreed upon and participants were provided role-playing time to practice presenting. They were also encouraged to practice as a group on their 
own time before the scheduled presentation delivery dates. A pre- and post-MHL survey was administered to all of the STs at this session.

The third and final tier of mental health training consisted of the delivery of small-group seminar presentations, lasting approximately 40 minutes, to students living in campus residences by teams; each team consisted of approximately two master trainers and three student trainers. Eight seminars were provided, with 22 seminar participants completing the same pre- and post-survey measure that was used with the student trainers.

\section{STATISTICAL ANALYSIS}

Completed surveys were entered into SPSS 22.0 and analyzed.

Mental health knowledge was assessed using 20 true/false questions. Correctly answered questions were assigned a score of 1 , while incorrectly answered questions were assigned a score of 0 . Scores were totalled and then converted into a percentage of correct answers. To assess attitudes, participants responded to eight different statements using a 7-point Likert scale $(1=$ strongly disagree to $7=$ strongly agree $)$ for each. Five of the items were reverse-coded; when all of the items were totalled, a higher score reflected a more positive attitude. Total scores on this measure could range from 8 to 56. To assess help-seeking efficacy, participants read a set of five statements and responded to each statement using the same 7-point Likert scale used to assess attitudes. These items were then totalled, with a higher score reflecting higher efficacy. Total scores on this measure could range from 5 to 35 .

MTs were given a different set of knowledge questions than the STs and seminar participants, but otherwise the surveys were the same across the participant groups. A series of paired-samples t-tests were used to compare pre- and post-test scores on each measure of interest (knowledge, attitudes, help-seeking) for each group of participants (MTs, STs and seminar participants). The data were screened for statistical assumptions of normality. The only time the assumptions were violated was for the attitudes measure within the student trainers group. The Wilcoxon Signed Rank test (non-parametric test) was run, but because the results were the same as the results obtained with the paired-samples t-test, only the t-tests are reported. Finally, where significant differences were obtained, Cohen's d was computed as a measure of effect size. Effect sizes were interpreted using Cohen's (1988) conventions (i.e., $0.2=$ small, $0.5=$ medium, $0.8=$ large).

\section{RESULTS}

\section{Participants}

In total, 51 pre- and post-test surveys were analyzed (surveys from 13 MTs, 16 STs, and 22 seminar participants). Available participant demographic information can be found in Table 1. A description of previous exposure to mental health training is reported in Table 2. Analyses are reported by participant group.

\section{Results by Participant Group}

Master trainers. Before training began, MTs correctly answered $51.9 \%$ of the knowledge questions.

Following training, they correctly answered $73.5 \%$ of the knowledge questions, a significant improvement 


\section{Table 1}

\section{Participant Demographics}

\begin{tabular}{lllllll}
\hline Participant Group & Gender & & Student Status & \multicolumn{2}{l}{$\begin{array}{l}\text { Any previous training in } \\
\text { mental health? }\end{array}$} \\
\cline { 2 - 7 } & Male & Female & Undergrad & Post-grad & No & Yes \\
\hline Master Trainers $(\mathrm{n}=13)$ & 1 & 12 & 12 & 1 & N/A & N/A \\
Student Trainers $(\mathrm{n}=16)$ & 4 & 12 & 14 & 2 & 2 & 14 \\
Seminar Participants $(\mathrm{n}=22)$ & 5 & 17 & 22 & 0 & 11 & 11 \\
\hline
\end{tabular}

Source: Authors' compilation.

\section{Table 2}

Previous Training in Mental Health (Student Trainers and Seminar Participants)

\begin{tabular}{|c|c|c|c|c|c|c|}
\hline \multirow{2}{*}{$\begin{array}{l}\text { Participant } \\
\text { Group }\end{array}$} & \multicolumn{2}{|c|}{$\begin{array}{l}\text { Previous } \\
\text { training (\%) }\end{array}$} & \multirow{2}{*}{$\begin{array}{l}\text { If "Yes," Type of Train- } \\
\text { ing Program (e.g., ASIST, } \\
\text { Mental Health First Aid) }\end{array}$} & \multirow{2}{*}{$\begin{array}{l}\text { Undergrad } \\
\text { Course }\end{array}$} & \multirow{2}{*}{$\begin{array}{l}\text { Work } \\
\text { Experience }\end{array}$} & \multirow{2}{*}{$\begin{array}{l}\text { More Than } \\
\text { One Source }\end{array}$} \\
\hline & No & Yes & & & & \\
\hline $\begin{array}{l}\text { Student } \\
\text { trainers } \\
(\mathrm{n}=16)\end{array}$ & 12.5 & 87.5 & 21.4 & 28.6 & 14.3 & 35.7 \\
\hline $\begin{array}{l}\text { Seminar } \\
\text { participants } \\
(\mathrm{n}=22)\end{array}$ & 50.0 & 50.0 & 9.1 & 27.3 & 54.5 & 9.3 \\
\hline
\end{tabular}

Source: Authors' compilation.

with a robust effect size: $\mathrm{t}(12)=6.49, \mathrm{p}<.01 ; d=1.8$. Regarding analysis of change in attitudes there was no significant improvement with training $(\mathrm{M}=51.9, \mathrm{t}(12)=-.92$, n.s. $)$. Regarding help-seeking efficacy, post-training scores demonstrated significant post-training improvement with a robust effect size $(\mathrm{M}=30.7$ vs. $28.9, \mathrm{t}(12)=2.76, \mathrm{p}<.05 ; d=0.77)$.

Student trainers. Before the training session, STs correctly answered $66 \%$ of the knowledge questions which significantly improved to $78 \%$ post training with a robust effect size: $\mathrm{t}(15)=4.39, \mathrm{p}<.001 ; d=1.1$. There was no significant improvement in attitude scores between pre-training $(\mathrm{M}=51.8)$ and post-training $(\mathrm{M}=51.3, \mathrm{t}(15)=-.55, \mathrm{n} . \mathrm{s})$. Post-training scores demonstrated significant improvement in help-seeking efficacy compared to pre-test: (pre-test $\mathrm{M}=29.4$ vs. post-test $\mathrm{M}=31.1 ; \mathrm{t}(15)=2.78, \mathrm{p}<.05 ; d=.70$ ). The effect size for this analysis is a medium effect.

Seminar participants. After the training session, seminar participants significantly improved knowledge scores: $\mathrm{t}(21)=8.41, \mathrm{p}<.001 ; d=1.79$ (a large effect), and help-seeking efficacy scores, $\mathrm{t}(21)=2.76$, 
Table 3

Pre- and Post-test Scores for Training Tiers

\begin{tabular}{llll}
\hline & Pre-test & Post-test & $p$ \\
\hline Knowledge (\% Correct, SD) & & & \\
$\quad$ Master trainers & $51.9(8.3)$ & $73.5(11.3)$ & $<.001$ \\
Student trainers & $65.9(12.7)$ & $78.4(9.6)$ & $<.001$ \\
$\quad$ Seminar participants & $59.8(10.6)$ & $85.7(8.2)$ & $<.001$ \\
Attitudes (/56, SD) & & & \\
Master trainers & $52.6(2.3)$ & $51.9(3.3)$ & n.s. \\
Student trainers & $51.8(4.5)$ & $51.3(5.4)$ & n.s. \\
Seminar participants & $50.4(4.4)$ & $50.8(5.1)$ & n.s. \\
Help-seeking Efficacy (/35, SD) & & & \\
Master trainers & $28.9(4.4)$ & $30.7(4.6)$ & $<.05$ \\
Student trainers & $29.4(4.0)$ & $31.1(4.2)$ & $<.05$ \\
Seminar participants & $27(4.7)$ & $28.6(4.3)$ & $<.05$ \\
\hline
\end{tabular}

Source: Authors' compilation.

$\mathrm{p}<.05 ; d=.59$ (a medium effect), as a result of exposure to the MHL seminar. Attitudes did not improve significantly: $\mathrm{t}(21)=.65$, n.s.

\section{DISCUSSION}

To our knowledge, this is the first report of a field test using a peer-led MHL seminar intervention on Canadian college campuses and the results (although interpreted with caution due to the relatively small sample size) suggest that this approach, using the Transitions resource and a brief PowerPoint presentation, may be feasible to apply and may have positive impact on improving various components of MHL in college students.

Our process used a peer-led seminar model to reach students living within campus residences. In that respect, it is similar to interventions previously reported in the United States of America, applied to address students' mental health related concerns (Kirsch et al., 2014; Thombs et el., 2015). In both of these reports, significant improvements in outcomes measures were realized, although in neither case was mental health literacy a focus of the interventions. Thus, to our knowledge, this report constitutes the first to use a peer-led seminar model in addressing MHL on college campuses.

We applied a waterfall distribution model, beginning with a small group of MTs and expanding to a larger group of STs who then were able to reach an even larger group of seminar participants. As all trainers were student volunteers, costs for this approach were minimal and were mostly driven by the one-day training session costs for MTs. In a similar vein, faculty time was voluntary and the Transitions resource and seminar presentation are both freely available online (TeenMentalHealth, 2013). Training and delivery time was not 
taxing: training was a full-day commitment for MTs, a one-and-one-half hour to two-hour commitment for STs and a 40-minute commitment for seminar participants. Total delivery time of the seminars in residences was approximately one-and-one-half hours for MTs and STs. The relatively low time commitment involved, and the minimal financial demand, means that the application of this approach may not only be feasible but fiscally responsible as well.

While the sample size was relatively small due to the short time during which this field test was implemented, overall we were able to demonstrate that this approach has promise as a vehicle for reaching students who are living on campus. We did not pair this intervention with a robust promotion strategy and thus many students may have not been aware that the seminars were available. In future research of this application we will need to ensure that residence students are well aware of the opportunity and perhaps consider potential incentives for attendance.

In terms of outcomes, this approach demonstrated significant and substantial improvements in knowledge and help-seeking efficacy in all participant groups. This finding is encouraging as previous exposure to mental health training (primarily through mental health first aid) was high in both the MT and ST groups but less common among the seminar participants. It suggests that even with previous training, there are robust additional benefits to be gained in MHL through this training program. How this seminar-based MHL exposure differs from other interventions previously experienced by participants is not clear, but may be the focus of future research.

Attitudes did not demonstrate significant improvement as a result of this intervention. This is likely due to the presence of a ceiling effect as attitudes towards mental health and mental disorders were highly positive in all groups (scores above 51/56). This finding is also encouraging as it demonstrates that mental health/mental disorder related stigma is not ubiquitous in this population of university students. However, the small sample size does not allow for conclusions about how common such positive attitudes might be. Seminar participants may have been those with low levels of stigma, while those who knew about the MHL seminar opportunity, but did not attend, may have higher levels of stigma. Furthermore, we cannot extrapolate from the data obtained in one small liberal arts campus to all Canadian post-secondary students. Further study of this issue is necessary.

In this study, we found evidence for improved knowledge and help-seeking in the absence of any improvements in attitudes. While there is a robust literature on the impact of stigma on help-seeking for mental disorders (Clement et al., 2015; Corrigan, Druss, \& Perlick, 2014; Eisenberg, Downs, Golberstein, \& Zivin, 2009; Yap, Reavley, \& Jorm, 2013) far less work has addressed the potential impact of improved knowledge on help-seeking in this population (Jorm, Christensen, \& Griffiths, 2005; Thornicroft, Rose, Kassam \& Sartorius, 2007). This is something that ought to be investigated in future studies that have larger samples and that have conducted research on different campus locations. It may be the case that knowledge improvement is a key element of improved help-seeking, and if so, would be consistent with current understanding of the importance of MHL as a foundation element for mental health promotion, prevention and care (Kutcher, Wei, \& Coniglio, 2016; Kutcher, Wei, Costa, Gusmao, Skokauskas, \& Sourander, 2016). This possibility cannot be explored here due to the small sample size, but would be worth investigating in future studies. 


\section{LIMITATIONS}

There were a number of limitations with this study. First, this was an initial uncontrolled field-test, addressing feasibility of the implementation and obtaining information about possible outcomes. While this was realized, the small sample size does not allow for conclusions outside of this work to be considered. However, given the robust outcomes in knowledge and help-seeking improvement in this small sample, it is likely that application of this approach on a wider scale would lead to positive results. A scale-up of this intervention using larger numbers and a controlled design is beginning.

Second, participants at all levels of training were self-selected, which means that it is possible that they were intrinsically motivated to learn more about mental health and mental disorders and that their baseline knowledge and attitudes would be better than in the general student population. However, if that is the case, we would expect to see even larger improvements in knowledge and help-seeking efficacy as well as improvements in attitudes in application of this intervention with the general student population. A study expanding this field test to a larger institution-wide intervention is currently beginning.

Third, the MTs and STs showed a significant improvement in knowledge following training but still did not achieve perfect scores on this portion of the post-test (i.e., there was still room to improve). In the future, the post-test could be used as a way to identify areas of training that could be reviewed or reinforced further with any given group of MTs or STs, since knowledge gaps have the potential to vary across different groups of trainers.

Finally, the field test took place at a small, rural Canadian, primarily undergraduate, university, which may not be representative of larger or more urban post-secondary institutions in Canada. For example, according to the enrolment figures listed on the Universities Canada (2015) website (http://www.univcan.ca/ universities/facts-and-stats/enrolment-by-university/) of the 96 universities in Canada, there are approximately 15 similarly sized universities. Several of these 15 universities are located in urban areas. Thus this work will need to be expanded to other types of post-secondary institutions as well before any broader conclusions about its impact can be determined.

\section{CONCLUSION}

Improving the mental health literacy of young or emerging adults is important for increasing knowledge, reducing the stigma associated with mental disorders and facilitating early identification of mental health problems and improving help-seeking behaviour (Milin et al., 2016). In this field-test we were able to demonstrate that using mental health content from Transitions (2nd edition), provided to students on campus through a waterfall distribution peer-based training model was both feasible and had significant and substantial positive impact on mental health knowledge and help-seeking efficacy. These robust results support the application of further research using larger samples and control methodology in the use of this model on post-secondary campuses. Such work, in which the authors are collaborating, is now underway.

Future research may also further focus on how improvements in MHL are linked to increases in the use of campus health or counselling services, or even an increase in information seeking with respect to the available services. 


\section{REFERENCES}

American College Health Association. (2013). American College Health Association-National College Health Assessment II: Undergraduate Student Reference Group Data Report Spring 2013. Hanover, MD: American College Health Association.

American College Health Association. (2016). American College Health Association-National College Health Assessment II: Undergraduate Student Reference Group Data Report Spring 2016. Hanover, MD: American College Health Association.

Best, K. L., Miller, W. C., Eng, J. J., \& Routhier, F. (2016). Systematic review and meta analysis of peer-led self-management programs for increasing physical activity. International Journal Of Behavioral Medicine. doi:10.1007/ s12529-016-9540-4

Brigham, T. A., Donahoe, P., Gilbert, B. J., Thomas, N., Zemke, S., Koonce, D., \& Horn, P. (2002). Psychology and AIDS education: Reducing high-risk sexual behaviour. Behavior and Social Issues, 12, 10-18.

Bulanda, J., Bruhn, C., Byro-Johnson, T., \& Zentmyer, M. (2014). Addressing mental health stigma among young adolescents: Evaluation of a youth-led approach. Health \& Social Work, 39(2), 73-80.

Canadian Association of College \& University Student Services and Canadian Mental Health Association. (2013). Post-Secondary Student Mental Health: Guide to a Systemic Approach. Vancouver, BC: Author.

Clement, S., Schauman, O., Graham, T., Maggioni, F., Evans-Lacko, S., Bezborodovs, N., Morgan, C., Rusch, N., Brown, J. S. L., \& Thornicroft, G. (2015). What is the impact of mental health-related stigma on help-seeking? A systematic review of quantitative and qualitative studies. Psychological Medicine, 48, 11-27.

Cohen, J. (1988). Statistical power analysis for the behavioral sciences (2nd ed.). Hillsdale, NJ: Lawrence Earlbaum Associates.

Corrigan, P. W., Druss, B. G., \& Perlick, D. A. (2014). The impact of mental illness stigma on seeking and participating in mental health care. Psychological Science in the Public Interest, 15(2), 37-70.

Eisenberg, D., Downs, M. F., Golberstein, E., \& Zivin, K. (2009). Stigma and help seeking for mental health among college students. Medical Care Research and Review, 66(5), 522-541.

Ettner, S. L., Frank, R. G., \& Kessler, R. C. (1997). The impact of psychiatric disorders on labor market outcomes. Industrial and Labor Relations Review, 51(1), 64-81.

Eysenbach, G., Powell, J., Englesakis, M., Rizo, C., \& Stern, A. (2004). Health related virtual communities and electronic support groups: Systematic review of the effects of online peer to peer interactions. BMJ, 328, 1-6.

Gulliver, A., Griffiths, K. M., \& Christensen, H. (2010). Perceived barriers and facilitators to mental health help-seeking in young people: A systematic review. BMC Psychiatry, 10, 113.

Holmes, A., Silvestri, R., \& Kostakos, M. (2011). The impact of mental health problems in the community college student population. Toronto: Higher Education Quality Council of Ontario.

Jorm, A. F., Christensen, H., \& Griffiths, K. M. (2005). The impact of Beyond Blue: The National Depression initiative on the Australian public's recognition of depression and beliefs about treatments. Australian and New Zealand Journal of Psychiatry, 39, 248-254.

Jorm, A. F., \& Kitchener, B. A. (2011). Noting a landmark achievement: Mental health first aid training reaches 1\% of Australian adults. Australian and New Zealand Journal of Psychiatry, 45, 808-813.

Kessler, R. C., Amminger, G. P., Aguilar-Gaxiola, S., Alonso, J., Lee, S., \& Ustun, T. B. (2007). Age of onset of mental disorders: A review of recent literature. Current Opinion in Psychiatry, 20(4), 359-64.

Kessler, R. C., Foster, C. L., Saunders, W. B., \& Stang, P. E. (1995). Social consequences of psychiatric disorders: Educational attainment. The American Journal of Psychiatry, 152(7), 1026-1032.

Kirsch, D. J., Pinder-Amaker, S. L., Morse, C., Ellison, M. L., Doerfler, L. A., \& Riba, M. B. (2014). Population-based initiatives in college mental health: Students helping students to overcome obstacles. Current Psychiatry Reports, 16, 525.

Kutcher, S. (2014). Transitions. 2nd ed. https://teenmentalhealth.org/toolbox/transitions-ebook/

Kutcher, S., Wei, Y., Costa, S., Gusmao, R., Skokauskas, N., \& Sourander, A. (2016). Enhancing mental health literacy in young people. European Child Adolescent Psychiatry, 25, 567-569.

Kutcher, S., Wei, Y., \& Morgan, C. (2015). Mental health literacy in post-secondary students. Health Education Journal, $1-9$. 
Kutcher, S., Wei, Y., \& Coniglio, C. (2016). Mental health literacy: Past, present and future. The Canadian Journal of Psychiatry, 61(3), 154-158.

Larsen, T. K., Melle, I., Auestad, B., Haahr, U., Joa, I., Johannessen, J. O.,...McGlashan, T. (2011). Early detection of psychosis: Positive effects on 5-year outcome. Psychological Medicine, 41, 1461-1469.

Lindsey, B. J. (1997). Peer education: A viewpoint and critique. Journal of American College Health, 45(4), $187-189$.

Mann, J. J. (2002). A current perspective of suicide and attempted suicide. Annals of Internal Medicine, $136(4), 302-311$.

McGorry, P. D., Purcell, R., Goldstone, S., \& Amminger, P. (2011). Age of onset and timing of treatment for mental and substance use disorders: Implications for preventive intervention strategies and models of care. Current Opinion in Psychiatry, 24, 301-306.

Mellanby, A. R., Rees, J. B., \& Tripp, J. H. (2000). Peer-led and adult-led school health education: A critical review of available comparative research. Health Education Research, 15(5), 533-545.

Milin, R., Kutcher, S., Lewis, S., Walker, S., Wei, Y., Ferrill, N, \& Armstrong, M. (2016). Impact of a mental health curriculum on knowledge and stigma among high school students: A randomized controlled trial. Journal of American Academy of Child and Adolescent Psychiatry, 55(5), 383-391.

Miyamoto, Y., \& Sono, T. (2012). Lessons from peer support among individuals with mental difficulties: A review of the literature. Clinical Practice \& Epidemiology in Mental Health, 8, 22-29.

Mojtabai, R., Stuart, E. A., Hwang, I., Eaton, W. W., Sampson, N., \& Kessler, R. C. (2015). Long-term effects of mental disorders on educational attainment in the National Comorbidity Survey ten-year follow-up. Social Psychiatry and Psychiatric Epidemiology, 50, 1577-1591.

Navaneelan, T. (July, 2012). Suicide rates: An overview. Statistics Canada, Catalogue no. 82-624-X. http://www.statcan. gc.ca/pub/82-624-X/2012001/article/11696-eng.pdf

O’Hagan, M., Cyr, C., McKee, H., \& Priest, R., (2010). Making the case for peer support report to the Mental Health Peer Support Project Committee of the Mental Health Commission of Canada (Canadian Electronic Library. Documents collection). Ottawa, Ont.: Mental Health Commission of Canada.

Parkin, S., \& McKeganey, N. (2000). The rise and rise of peer education approaches. Drugs: Education, Prevention and Policy, 7(3), 293-310.

Perkins, D. O., Gu, H., Boteva, K., \& Lieberman, J. A. (2005). Relationship between duration of untreated psychosis and outcome in first-episode schizophrenia: A critical review and meta-analysis. American Journal of Psychiatry, 162, 1785-1804.

Potvin-Boucher, J., Szumilas, M., Sheikh, T., \& Kutcher, S. (2010). Transitions: A mental health literacy program for post-secondary students. Journal of College Student Development, 51(6), 723-727.

Prince, J. P. (2015). University student counseling and mental health in the United States: Trends and challenges. Mental Health \& Prevention, 3, 5-10.

Rickwood, D., Deane F. P., Wilson, C. J., \& Ciarrochi, J., (2005). Young people's help-seeking for mental health problems. Australian e-Journal for the Advancement of Mental Health, 4(3), 1-34.

Reavley, N. J., McCann, T. V., \& Jorm, A. F. (2012). Actions taken to deal with mental health problems in Australian higher education students. Early Intervention in Psychiatry, 6, 159-165.

Ross, A. M., Hart, L. M., Jorm, A. F., Kelly, C. M., \& Kitchener, B. A. (2012). Development of key messages for adolescents on providing basic mental health first aid to peers: A Delphi consensus study. Early Intervention in Psychiatry, 6, 229-238.

Scott, D., \& Happell, B. (2011). The high prevalence of poor physical health and unhealthy lifestyle behaviors in individuals with severe mental illness. Issues in Mental Health Nursing, 32, 589-597.

Storrie, K., Ahern, K., \& Tuckett, A. (2010). A systematic review: Students with mental health problems-A growing problem. International Journal of Nursing Practice, 16, 1-6.

TeenMentalHealth. (2013). Transitions. http://teenmentalhealth.org/product/transitions/

Thombs, D. L., Reingle Gonzalez, J. M., Osborn, C. J., Rossheim, M. E., \& Suzuki, S. (2015). Resident assistant training program for increasing alcohol, other drug, and mental health first-aid efforts. Prevention Science, 16(4), $508-517$.

Thornicroft, G., Rose, D., Kassam, A., \& Sartorius, N. (2007). Stigma: Ignorance, prejudice or discrimination? British Journal of Psychiatry, 190, 192-193.

Universities Canada. (2015). Enrolment by university. http://www.univcan.ca/universities/facts-and-stats/ enrolment-by-university/ 
White, S., Park, Y. S., Israel, T., \& Cordero, E. D. (2009). Longitudinal evaluation of peer health education on a college campus: Impact on health behaviors. Journal of American College Health, 57(5), 497-506.

Yap, M. B. H., Reavley, N. J., \& Jorm, A. F. (2013). Associations between stigma and help-seeking intentions and beliefs: Findings from an Australian national survey of young people. Psychiatry Research, 210, 1154-1160. 